\title{
RESEÑAS BIBLIOGRAFICAS
}

AKERLOF, George A. Aneconomic Theorist's book of tales, Cambridge, Cambridge University Press, $1986,196 \mathrm{p}$.

La presente obra está conformada por una serie de ensayos ya publicados separadamente durante el periodo 1970.1983 en prestigiosas revistas . American EconomicReview - The Quarterly Journal of Economics y The Review of Economic Studies. Es un acierto que la Cambridge University Press brinde ahora la posibilidad de disponer de tales ensayos integrados en una única obra ya que los temas que tratan, sí bien pueden parecer por demás diversos, se inscriben, sin embargo, en una misma problemática: la metodológica.

Esencialmente. el propósito de Akerlof - capitulo 1 - consiste en demostrar que los supuestos neoclásicos del equilibrio general, competencia perfecta, conducta racional, etc., limitan la validez científica de la explicación en Economía. Cómo explicar, se pregunta, de forma consistente con el supuesto de maximización individual, problemas tales como el desempleo involuntario prolongado o la discriminación. Su propuesta -más bien aventurada- es considerar nuevos supuestos de comportamiento, alternativos de los tradicionales, $y$ analizar las implicaciones de teoria económica que se derivan de los mismos. Esta problemática, sostiene, abre un nuevo campo de investigación. tal como ocurrió en la década de los años cincuenta con la economía matemática. Akerlof se propone establecer las hipótesis de comportamiento de los agentes económicos incorporando los avances logrados en la psicología, la sociología y la antropología.

El cuerpo de la obra está conformado por ocho capítulos dedicados a tratar una vasta problemática sobre el tema de supuestos no convencionales. El capítulo 2 considera las implicaciones de la información asimétrica y costosa sobre el mecanismo de mercado; ilustra la investigación con el caso de los autos usados, los sectores del seguro y algunos mercados de trabajo. En el capitulo 3 se analizan ciertas conductas económicas que difieren sustancialmente de aquellas supuestas en el modelo de equilibrio Walrasiano: se trata de considerar indicadores -más ricos dice Akerlof- de naturaleza antropológica y sociologica que explican y predicen conductas y habilidades hasadas en la raza, castas, clases sociales, religión, etc. Los modelos convencionales suponen que una conducta económica cualquiera no afecta actos económicos posteriores. Sin embargo. En una economía de castas por ejemplo, cualquier transacción que transgreda los tabuies modifica la conducta posterior hacia el transgresor. A continuación (capitulo 4) el autor introduce criterios para identificar distintas categorias de agentes económicos y los aplica al sistema impositivo, a partir del modelo de Mirrless - Fair, a los programas de fuerza laboral y de hienestar social: analiza luego las ventajas y desventajas de tales criterios de clasificación en los tres dominios considerados. El tema del capitulo 5 está referido a un modelo de mercado de trabajo en el que se introduce el supuesto de la vigencia de un código de conducta social al que adhiere cierto sector de la sociedad. Por ende. la función de utilidad, además de las preferencias personales, incorpora variables tales como la reputación en la comunidad y grado de obediencia a las pautas de comportamiento social. Tal función -con fundamento antropológicodifiere de la neoclásica, esencialmente individualista. El mercado laboral también es el tema del 
capitulo 6. En este caso se analizan aspectos tales como el grado de utilización de la mano de obra, la distinción -novedosa dice el autor-entre tecnología y capital humano, los casos de empleo con baja elasticidad salario de la demanda. El capitulo 7 esta dedicado a estudiar un modelo de decisión que difiere del que supone la conducta racional. Se establecen supuestos de naturaleza psicologica.

Aquí la elección responde más a pautas de creencias que a razones de información. Así se explica, por ejemplo, por que la publicidad no informativa es efectiva. El Capitulo 8 incorpora un microfundamento sociológico en los modelos de contratos implícitos de trabajo basado en normas de conducta observadas, reciprocamente, por los trabajadores y las firmes, se trata de un aspecto original, diferente del modelo de mercado puro, en donde las partes aumentan su función de utilidad intercambiando elementos no pecuniarios como afecto, lealtad, etc- el gift exchange- En el capitulo 9 se analiza cómo los cambios, aunque parciales, de valoraciones de los individuos afectan sus elecciones. Este enfoque aparece como más explicativo que el supuesto tradicional de los valores inmutables. Asociado a tal hipótesis de cambios se estudian. minuciosamente, las implicaciones de cientas motivaciones -pertenencia a una clase social, lealtad institucional,elite- respecto del objetivo de maximización del bienestar.

An Economic Theorist's Book of Tales constutiye todo un desafio para la economía vigente por cuanto analiza las implicaciones de teorfa economica que se deducen de lo que Akerlof denomina la cuasi racionalidad "near rationality". Comportamiento que encuentra su explicación a partir del enfoqué interdisciplinario, con aspecto antropológicos, psicológicos y sociológicos. Un programa de investigación como el propuesto, que amplíe la comprensión de los hechos económicos, resulta de interés para la ciencia. Sin embargo, su vigencia es aun incipiente. Sólo una perspectiva temporal permitira juzgar los aportes de este nuevo enfoque.

Elaborados con rigurosidad rérica, riqueza en la caraterización de ejemplos de los más diversos paises y claridad de estilo estos ensayos revisten interts tanto para estudiantes avanzados como para quienes cultivan y enset̃an nuestra disciplina, especiạmente en los campos de la metodología y de la economía laboral.

E. O. de Guevara 